\title{
A study on the Legal System of Endowment Insurance for the Lost Only-child Elderly in China
}

\author{
Fan Zhang \\ School of Public Administration \\ University of Electronic Science and Technology of China \\ Chengdu, P.R. China \\ 115182330@qq.com
}

\author{
Xueyuan Tang \\ School of Public Administration \\ University of Electronic Science and Technology of China \\ Chengdu, P.R. China \\ 657889720@qq.com
}

\begin{abstract}
With the increasing of the lost only-child elderly, to protect their legitimate rights. Solving the legal security system problems such as the security system is unsound, the regulations are not specific, and the guarantee remains weak. This paper draws the following three conclusions through literature analys is. We can improve the legal system of the endowment insurance for the lost only-child elderly, refine the legal provisions for the endowment insurance for the elderly, and optimize the adult adoption system. Through these three aspects, the goal to protect lost only-child elderly live in a dignified and healthy old age will come true.
\end{abstract}

Keywords - lost only-child elderly, endowment insurance, legal system, suggestion

\section{The ApPeARAnce BaCKGRound AND Demands OF LOST ONLY-CHILD ELDERLY}

\section{A. The Appearance Background of Lost Only-child Elderly}

The proportion of the elderly population in China is still growing, which makes the problem of old-age care increasingly prominent. As a special product under the family planning policy, the "lost only-child elderly" is a special elderly group who had only one child in the young under the family planning policy, but the only child is suffering from an unpredictable death when they gradually entered the old age and lost fertility. By 2010, according to relevant surveys, the cumulative number of single-child deaths was one million three thousand. With the accelerating process of aging, most elderly have only one child, and the only child will increase the risk of survival with the increase of age so that the total amount of death of single child will increase even faster. It is estimated that the total number of families who lose their children will reach 11 million by 2050 .

\section{B. Demands of Lost Only-child elderly}

\section{1) The demand of economic security}

For a long time in China, there is a concept of "raising children to protect the old", and the purposes of having children is to gain sources of income from their children when they are old. The elderly who lost their children have lost the source of most of their financial support. For those who have no fixed income, they live mainly on meager pensions, which do not make them meet the food and clothing. For those who have fixed incomes, although they have no problem in maintaining basic life, most of them are not enough to support social pension services when they are getting older.

\section{2) The demand of medical security}

The old people lost their children in the middle age often makes them fall into a depressed mental state and the longterm depression will increase the probability that the elderly will suffer from senile diseases as well as the physical condition of the lost only-child elderly is getting worse and worse. The results of the survey showed that the elderly who lost their only child were distributed on average 100 per unit, at least 50 had chronic diseases and 15 had a major disease [1]. According to a national sample survey of the "Special Family Assistance" program of the China Family Planning Association in 2013, 67.8\% of the lost only-child elderly hope to meet the demand for medical insurance first, and the demand for medical insurance accounts for the highest proportion, and ranks first among various needs.

\section{3) The demand of mental satisfaction}

The family structure with the only child is an "inverted triangle" family model composed between husband and wife and the only child. Mr. Fei Xiaotong pointed out that the bottom vertex of the single child's inverted triangle is the only pivot of the triangle to be stable. The loss of the"unique pivot" will mean the absence of the entire family element and the no return of the "two sides", which leads to the collapse of the family triangle structure. [2] According to the survey, normal old people usually have $1 / 4$ negative emotions such as melancholy, impetuosity and sentimentality,[3] but almost all of the elderly who have lost their children have these negative emotions and they are very sensitive and fragile in spirit. They have long been immersed in the grief of losing their children. More than two-thirds of the elderly who have lost their children suffers from different degrees of depression, and more than one-half of them has had suicidal tendencies [4].

\section{4) The demand of social reintegration}

Most lost only-child old man will get psychological comfort by escaping. Some of them will go away from their homes to a completely strange environment to live, to close themselves up and not to be in contact with the society. Some people attribute their misfortunes to the family planning policy, generate a strong sense of deprivation, dissatisfaction with society, and even make some extreme things to express their resentment. Exclusion of society will make them unable to live normally, and they need to integrate into society again. 


\section{The Necessity of providing legal protection for the Lost Only-child Elderly}

1) The Necessity of providing legal protection for the Lost Only-child Elderly

The consistency principle of rights and obligations means that citizens' rights and obligations are consistent. Rights are the basis for fulfilling obligations and obligations are the premise of rights. Citizens are both rights holders and obligations undertakers. A citizen who exercises a certain right must undertake corresponding obligations, as well as a citizen must enjoy certain rights after fulfilling certain obligations. The relationship between rights and obligations should reflect fairness and justice, which is the essence of rights and obligations. [5] In the constitution of China, family planning is determined to be a citizen's obligation in the form of basic law. Then, after fulfilling its obligations, the citizen should enjoy the right that the country provides old-age security.

\section{2) The Consistency Principle of Right and Responsibility}

The consistency principle of rights and responsibilities means that the rights of the manager in the organization is consistent with the responsibilities he should bear. Right and responsibility are indivisible, and you must bear the corresponding responsibilities in order to exercise any kind of rights. For state power, this principle requires that the powers of the state should be consistent with its responsibilities. China's family planning policy is a manifestation of the state's exercise of power to limit citizens' reproductive rights. There is an inevitable connection between the emergence of the lost only-child elderly and the family planning policy. Therefore, it is the responsibility of the State to provide assistance to citizens who are affected by the performance of their family planning obligations.

\section{PROBlems IN THE LegAl SySTEM OF ENDOWMENT INSURANCE FOR THE LOST ONLY-CHILD ELDERLY}

\section{A. Low Level of Legislation and Imperfect System}

Generally speaking, if the system is related to interests, it will be necessary to have a clear legal provisions on the rights and obligations of the interest groups. At present, China's laws on the endowment insurance for the lost only-child elderly are mainly the Population and Family Planning Law and the Rights Protection Law. The two laws mainly stipulate the principle of the old-age security system for the elderly. And the specific standards and methods are stipulated by the local regulations, department rules and even the normative documents below the regulations, and these regulations are more dispersed. Therefore, the lost only-child elderly often have an unacceptable situation when they lack the selfsupporting ability and they are unable to receive state assistance.

\section{B. The abstraction of Law and Lack of Maneuverability}

There is no specific legislation for the lost only-child old man. Population and Family Planning Law stipulates that the elderly who lost their children have the right to receive assistance, but there is no clear regulation on how to help. Rights Protection Law stipulates that the state should provide assistance to those who do not have the ability to work, have no source of income, and have no supporters. And the standard of assistance for the lost only-child elderly is based on that three factors. However, for many lost only-child elderly people with fixed incomes in cities and towns, their main needs are spiritual rather than material. In this respect, they are very different from the "three nos" old people so the reference to the support criteria for the "three noes" old people does not meet the main needs of the lost only-child elderly. Therefore, the content, standards and scope of support for the lost only-child elderly have yet to be further clarified.

\section{The weak of Social System and Mental Satisfaction}

On the one hand, in terms of material level, there are special support funds for the lost only-child elderly. Since 2014, the standard for special assistance has improved 340 yuan per person per month in urban areas and 170 yuan per person per month in rural areas, which compared with the average consumption level in the region, it is obviously low. According to the statistics of the National Health and Family Planning Commission, in 2014, only 470,000 lost only-child elderly people received this special assistance, and the coverage rate of the special funds was seriously low. On the other hand, at the present stage, in terms of the spirit level, the legal guarantee of the lost only-child elderly in our country is mainly concentrated on the material level. However, the difficulty of supporting the lost only-child elderly is not only in the material aspect, but more importantly, in the spiritual aspect. They often have a variety of mental problems after a great blow to their spirits, and the legislators have not yet fully considered it.

\section{The Perfection of the Legal System of the Lost ONLY-CHILD ELDERLY}

\section{A. The Improvement of the Old-age Security System for the Lost only-child Elderly}

The improvement of the legal guarantee system for the lost only-child elderly should be carried out under the existing legal framework without separate legislation. The following factors should be considered in the improvement of the system according to the above ideas: First, it should reflect the inclusiveness of the law. The group who lost their children is huge and their identities are different. Some of them are within the scope of the social security system, and others are not. The law should take into account the differences within the group and design a differentiated legal system to protect the needs of them. Second, after perfecting the legal system of the endowment insurance for the lost only-child elderly, the local governments should formulate some local laws and regulations in accordance with the local conditions according to the law, and form a perfect legal system that is based on the law and the local laws and regulations. 


\section{B. Refining the Relevant Provisions of the Old-age Security for the Lost only-child elderly}

1) Concertize the provisions of the population and family planning law.

Population and Family Planning Law stipulates that the only-child family may be assisted in accordance with state regulations if the only child suffers from disability or death. The rule is too vague and cannot be used as the basis for the endowment insurance for the elderly. It can be modified as follows: First, the scope of the family that lost their child is clearly fixed as the couple who have not re-born after the death of the only child and the woman is over 49 years old. The lost only-child elderly should reach the age of 60 at the same time if they meet the above conditions. Secondly, because the law should be stable, it is not appropriate to stipulate the amount of specific support funds in the law. However, the calculation standard for the old-age security for the lost only-child elderly should be linked to the local consumption level and determined in the form of law. Local regulations everywhere can set a standard no lower than this standard.

\section{2) Add special provisions in the rights protection law for} the lost only-child old man.

There is currently no specific provision in the law for the lost only-child elderly. As far as material assistance is concerned, the law only supports the lost only-child elderly in accordance with the standards of the "three nos" elderly. Because of the difference between them, it is impossible to classify the lost only-child elderly into the "three nos" elderly people. The scope should be classified as a separate subject for special protection. In terms of spiritual comfort, the current protection of the spiritual rights of the elderly is mainly children, which is not applicable to the lost only-child elderly. Therefore, the grassroots self-governing organizations such as the community and the neighborhood committee can be used to protect the spiritual rights and interests of the lost onlychild elderly. In these organizations, the talents of applied psychology are directly recruited, and free treatment for the elderly who have mental illness is free of charge. This part of the cost is supported by the state finance.

\section{Increase the Adoption System for Adults}

The system of adoption is designed to formulate a legal parent-child relationship between an unrelated adopter and the adoptee,[6] which allows the elderly to take their adopted children as their new spiritual sustenance, so that they can get out of the shadow of the loss of their only child. China's Adoption Law stipulates that ordinary adoptions can only adopt youths under the age of fourteen, and adults can not be adopted. The reason is that adults do not need to be adopted, and it is difficult to establish deep feelings between adopters and adoptees. But in fact, adults are not unwilling to be adopted, especially the common emotional needs between adults and the lost only-child elderly needs to make the adult adoption system a reality.

The adult adoption system is designed as follows. First, the conditions of adult adoption for a lost-child family. The women of the lost-child family should be more than 49 years old and have no infectious diseases or major diseases. This is mainly to consider the actual interests of the adopters, and can not increase the material burden of the adoptees. Second, the establishment of adoption relationship is the result of mutual agreement. In order to establish the adoption relationship, both the adopter and the adoptee must make an expression to agree with the relationship. If the adoptee's parents are alive, the adoptive relationship does not interrupt the rights and obligations between the adoptee and the biological parents. In order to avoid future conflicts, it should also seek the consent of the parents of the adoptees. Third, set up a trial adoption period. China's Adoption Law stipulates that the establishment of the adoption relationship is registered as the effective requirement. As long as the agreement between the adopter and the adopted person is reached, the trial period begins, and the duration is 6 months. During six-month run-in, the two parties should perform their obligations to each other. After the end of the trial period, if both parties still have the agreement to reach an adoption relationship, the adoption relationship will be registered in the relevant departments that means it is established. If the two parties do not agree to reach an adoption relationship, the adoption relationship will not be established. The establishment of this system is mainly to give the two sides a period of thinking and avoid the adverse consequences of impulsive behavior.

\section{CONCLUSION}

The demands of the lost only-child elderly in China mainly include four aspects, including economic, medical, emotional satisfaction and social reintegration. The paper fully considers the special needs of the group when designing the system. The demand for economic, medical and social reintegration can be realized through the perfection of the legal system and specific legal provisions. The demand for emotional satisfaction can be realized through the adoption system of the adult. From a legal point of view, we care for the lost only-child elderly from the material to the spiritual level so that they can enjoy their old age.

\section{REFERENCES}

[1] Xiangdong Su, Who will comfort the pain of China's "lost-child family”, China observed, July 2012. (In Chinese)

[2] Xiaotong Fei, Native China and Fertility System, Tianjin People's Publishing House, 1989, pp.39. (In Chinese)

[3] Sumei wan, Elderly Psychology and Quality of Life, Journal of Hubei Normal University: Natural Science Edition, 2006. (In Chinese)

[4] Jiyan Lin, Current Situation and Countermeasure Analysis of the Lost Families in China, 2012, pp.121. (In Chinese)

[5] Xunxin Yan, "Rights and Obligations, Powers and Responsibilities", China University of Political Science and Law Press, pp.28, January 2014. (In Chinese)

[6] Yanman Yu, The Law of Relatives, Law press, pp.405, September 2007.

[7] Zhen Li and An Yan, Questions on the Old People Lost Alone: Difficulties, Institutional Causes and Solutions, Journal of Huanghe University of Science and Technology. January 2015, pp.65-69. (In Chinese)

[8] Guoping Wu. Legislation for the Elderly's Elders' Rights and Interests, Social Welfare, April 2017, pp.35-39. (In Chinese) 
[9] Bingju Guo, The Dilemma and Outlet of Social Security for the Lost Only-child Elderly in China, Administration and Law, January 2015. (In Chinese)
[10] Mengying Li, Discussion on the Difficulties and Countermeasures of the Endowment of Lost Only-child Families, Law and Society, April 2016, pp.163-164. (In Chinese) 